\title{
Guidelines
}

HORMONE

RESEARCH IN

PAEDIATRICS
Horm Res Paediatr 2019;92:1-14

DOI: 10.1159/000502231
Received: June 4, 2019

Accepted: July 18, 2019

Published online: September 12, 2019

\section{Diagnosis, Genetics, and Therapy of Short Stature in Children: A Growth Hormone Research Society International Perspective}

Paulo F. Collett-Solberg ${ }^{\mathrm{a}}$ Geoffrey Ambler ${ }^{\mathrm{b}}$ Philippe F. Backeljauw ${ }^{\mathrm{c}}$ Martin Bidlingmaier ${ }^{\mathrm{d}}$ Beverly M.K. Biller ${ }^{\mathrm{e}}$ Margaret C.S. Boguszewski ${ }^{f}$ Pik To Cheung ${ }^{g}$ Catherine Seut Yhoke Choong ${ }^{\text {h-j }}$ Laurie E. Cohen ${ }^{k}$ ${\text { Pinchas Cohen' }{ }^{\prime} \text { Andrew Dauber }}^{m}$ Cheri L. Deal $^{n}$ Chunxiu Gong ${ }^{\circ} \quad$ Yukihiro Hasegawa $^{p}$ Andrew R. Hoffman ${ }^{q}$ Paul L. Hofman ${ }^{r}$ Reiko Horikawa ${ }^{\mathrm{s}}$ Alexander A.L. Jorge ${ }^{\mathrm{t}}$ Anders Juul ${ }^{\mathrm{u}}$ Peter Kamenický ${ }^{v}$ Vaman Khadilkar $^{\mathrm{w}}$ John J. Kopchick ${ }^{x}$ Berit Kriström ${ }^{y}$ Maria de Lurdes A. Lopes ${ }^{z}$ Xiaoping Luo ${ }^{A}$ Bradley S. Miller $^{B}$ Madhusmita Misra $^{C}$ Irene Netchine ${ }^{\mathrm{D}}$ Sally Radovick ${ }^{\mathrm{E}}$ Michael B. Ranke ${ }^{\mathrm{F}}$ Alan D. Rogol ${ }^{\mathrm{G}}$ Ron G. Rosenfeld ${ }^{\mathrm{H}}$ Paul Saenger' Jan M. Wit Joachim Woelfle ${ }^{\mathrm{K}}$

aDisciplina de Endocrinologia, Departamento de Medicina Interna, Faculdade de Ciências Médicas, Universidade do Estado do Rio de Janeiro, Rio de Janeiro, Brazil; ' ${ }^{b}$ Institute of Endocrinology and Diabetes, The University of Sydney, Sydney, NSW, Australia; 'Division of Endocrinology, Department of Pediatrics, Cincinnati Children's Hospital Medical Center, University of Cincinnati College of Medicine, Cincinnati, OH, USA; ${ }^{d}$ Endocrine Laboratory, Medizinische Klinik und Poliklinik IV, Klinikum der Universität München,

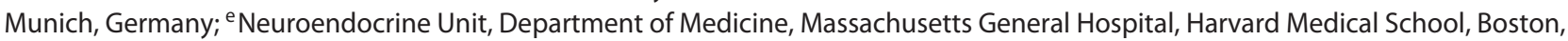
MA, USA; ${ }^{\mathrm{f}}$ Department of Pediatrics, Federal University of Parana, Curitiba, Brazil; ${ }^{9}$ Paediatric Endocrinology, Genetics, and Metabolism, Virtus Medical Group and The University of Hong Kong, Hong Kong SAR, China; ' Department of Endocrinology, Perth Children's Hospital, Child and Adolescent Health Service, Perth, WA, Australia; 'Division of Paediatrics, School of Medicine, University of Western

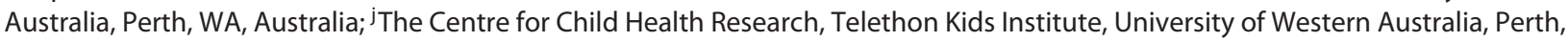
WA, Australia; 'Division of Endocrinology, Boston Children's Hospital, Harvard Medical School, Boston, MA, USA; 'Leonard Davis School of Gerontology, University of Southern California, Los Angeles, CA, USA; m Division of Endocrinology, Children's National Health

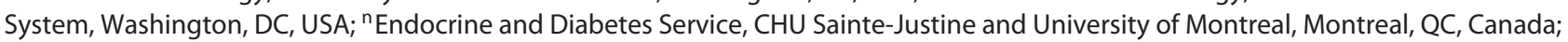
${ }^{\circ}$ Endocrinology, Genetics, and Metabolism, Beijing Diabetes Center for Children and Adolescents, Medical Genetics Department, Beijing

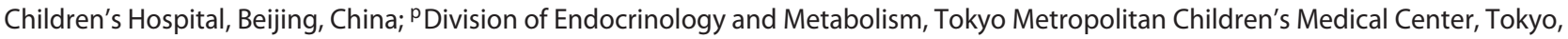
Japan; 'Department of Medicine, Stanford University School of Medicine and VA Palo Alto Health Care System, Palo Alto, CA, USA; 'Liggins Institute, University of Auckland, Auckland, New Zealand; ${ }^{\mathrm{D}}$ Division of Endocrinology and Metabolism, National Center for Child Health and Development, Tokyo, Japan; ' Unidade de Endocrinologia Genética (LIM25), Hospital das Clínicas, Faculdade de Medicina, Universidade de São Paulo, São Paulo, Brazil; "Department of Growth and Reproduction, Rigshospitalet, University of Copenhagen, Copenhagen, Denmark; ' Service d'Endocrinologie et des Maladies de la Reproduction, Hôpital de Bicêtre, Assistance Publique-Hôpitaux de Paris, Université Paris-Saclay, Paris, France; 'WHirabai Cowasji Jehangir Medical Research Institute (HCJMRI), Jehangir Hospital, Pune,

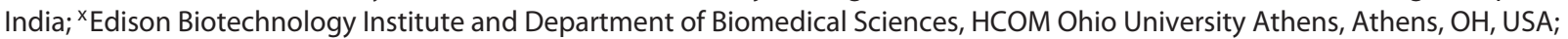
${ }^{y}$ Institute of Clinical Science, Pediatrics, Umeå University, Umeå, Sweden; ${ }^{z}$ Unidade de Endocrinologia Pediátrica, Area da Mulher, Criança e Adolescente, Centro Hospitalar Universitário de Lisboa Central-Hospital de Dona Estefânia, Lisbon, Portugal; ${ }^{A}$ Department of Pediatrics, Tongji Hospital, Tongji Medical Colleage, Huazhong University of Science and Technology, Wuhan, China; ${ }^{B}$ Division of Endocrinology, Department of Pediatrics, University of Minnesota Masonic Children's Hospital, Minneapolis, MN, USA; ${ }^{C}$ Division of Pediatric Endocrinology, Massachusetts General Hospital and Harvard Medical School, Boston, MA, USA; ${ }^{D}$ Explorations Fonctionnelles Endocriniennes, AP-HP Hôpital Trousseau, Centre de Recherche Saint Antoine, INSERM, Sorbonne Université, Paris, France; EDepartment of Pediatrics, Robert Wood Johnson Medical School, Child Health Institute of New Jersey-Rutgers University, New Brunswick, NJ, USA; FUniversity Children's Hospital, Tübingen, Germany; ${ }^{G}$ Department of Pediatrics, University of Virginia, Charlottesville, VA, USA; ${ }^{H}$ Oregon Health and Science University, Portland, OR, USA; 'NYU Winthrop Hospital, Mineola, NY, USA; JDepartment of Pediatrics, Leiden University Medical Center, Leiden, The Netherlands; KPediatric Endocrinology Division, Children's Hospital, University of Bonn, Bonn, Germany

The views expressed in this article are personal and not necessarily the views of the European Medicines Agency, the Committee for Medicinal Products for Human Use, or the Medical Products Agency.

\section{KARGER}

E-Mail karger@karger.com www.karger.com/hrp

\section{(c) 2019 The Author(s)}

Published by S. Karger AG, Basel

Karger

Open access

This article is licensed under the Creative Commons Attribution NonCommercial-NoDerivatives 4.0 International License (CC BYNC-ND) (http://www.karger.com/Services/OpenAccessLicense) Usage and distribution for commercial purposes as well as any distribution of modified material requires written permission.
Paulo Ferrez Collett-Solberg, MD, PhD

Pavilhão Reitor Haroldo Lisboa da Cunha, térreo

Rua São Francisco Xavier 524, Maracanã

Rio de Janeiro 20550-013 (Brazil)

E-Mail paulosolberg@yahoo.com 


\section{Keywords}

Growth · Pediatrics · Guideline · Growth hormone ·

Treatment

\section{Abstract}

The Growth Hormone Research Society (GRS) convened a Workshop in March 2019 to evaluate the diagnosis and therapy of short stature in children. Forty-six international experts participated at the invitation of GRS including clinicians, basic scientists, and representatives from regulatory agencies and the pharmaceutical industry. Following plenary presentations addressing the current diagnosis and therapy of short stature in children, breakout groups discussed questions produced in advance by the planning committee and reconvened to share the group reports. A writing team assembled one document that was subsequently discussed and revised by participants. Participants from regulatory agencies and pharmaceutical companies were not part of the writing process. Short stature is the most common reason for referral to the pediatric endocrinologist. History, physical examination, and auxology remain the most important methods for understanding the reasons for the short stature. While some long-standing topics of controversy continue to generate debate, including in whom, and how, to perform and interpret growth hormone stimulation tests, new research areas are changing the clinical landscape, such as the genetics of short stature, selection of patients for genetic testing, and interpretation of genetic tests in the clinical setting. What dose of growth hormone to start, how to adjust the dose, and how to identify and manage a suboptimal response are still topics to debate. Additional areas that are expected to transform the growth field include the development of long-acting growth hormone preparations and other new therapeutics and diagnostics that may increase adult height or aid in the diagnosis of growth hormone deficiency.

\footnotetext{
(C) 2019 The Author(s) Published by S. Karger AG, Basel
}

\section{Introduction and Background}

The Growth Hormone Research Society (GRS) convened a 3-day workshop to provide an expert perspective on the diagnosis and therapy of short stature in children [1]. Short stature and growth deceleration are common pediatric concerns [2]. Although established diagnostic and management paradigms exist, recent advances in molecular technologies have greatly broadened our understanding of the genetic causes of short stature, and this is altering our approach to children with these common problems. In particular, while evaluation of the growth hormone (GH)-insulin-like growth factor-I (IGF-I) axis is often part of the initial clinical assessment in growth disorders, the evolving understanding of growth plate physiology has led to an increasing focus on abnormalities in this tissue resulting in the potential for the development of innovative therapies [3]. In addition, discovery of novel mutations in genes encoding proteins responsible for pituitary development has increased our understanding of the genetic basis of hypopituitarism. The increased capability and availability of genetic and epigenetic testing in clinical practice has the potential to enhance the diagnostic process and inform appropriate treatment. Furthermore, novel treatment approaches, including use of long-acting GH formulations as well as new GH secretagogues that may serve both as diagnostic tools and as therapeutic agents, have prompted expert consideration.

\section{Methods}

The structure of this Workshop was adapted from prior workshops organized by the GRS [4]. The Program Organizing Committee invited $46 \mathrm{GH}$ experts from 14 countries across 5 continents. These included pediatric and adult endocrinologists, basic scientists, representatives from the European Medicines Agency and the United States Food and Drug Administration, and representatives from the pharmaceutical industry. A review of the status of GH therapy and evaluation of short stature in children was published prior to the meeting [2].

Following presentations that summarized the relevant literature, 3 breakout groups addressed each topic in greater detail by discussing a list of questions formulated by the Program Organizing Committee and subsequently agreed upon by all participants. All attendees reconvened after each breakout session to share reports from the groups. At the end of days 1 and 2, a writing team compiled the breakout group reports into a document that was discussed and reviewed in its entirety and revised by participants on the final day. In a few cases where there was not a clear consensus, the majority opinion was determined by a vote of the participants. This draft document was edited further for formatting and references, and subsequently circulated to the academic attendees for final review after the meeting. Participants from pharmaceutical companies and regulatory agencies who were present at the Workshop joined in the breakout session debates but were not part of the writing team, did not 
vote, and were not present during text revision on the final day. They were shown the manuscript prior to submission but only to identify any factual errors, and they noted none.

Studies used in this analysis were conducted within ethical standards. This publication about a meeting held with scientific and regulatory experts to review published data is exempt from ethics committee approval.

\section{Evaluation of Children with Short Stature and/or Growth Deceleration}

Referral criteria have been developed for health care providers aimed at early detection of growth disorders based on a combination of low height standard deviation score (SDS), discrepancy from target height, and growth deceleration [5-7]. Although WHO growth charts can be utilized for children up to 2 years of age, local growth charts, when available, are more appropriate for older children [8].

The evaluation of short stature has been described previously $[1,2,9,10]$. The medical history should include information about consanguinity, use of assisted reproductive technologies, gestation, birth weight, length, head circumference, and family history including pubertal timing and anthropometry of relatives. In addition, it is important to elicit symptoms concerning hypothyroidism, precocious or delayed puberty, systemic causes of poor growth, and neurological symptoms. A full physical examination should be performed with special attention to dysmorphic features and body proportions.

In most instances, it is important to ensure repeated and accurate auxologic measurements. Children with any of the following characteristics should be considered for evaluation of pathology: short stature with a height SDS below -2 , height that clearly deviates from the familial background $[5,11,12]$, or a significant decrease in height SDS (i.e., a deflection of at least $0.3 \mathrm{SDS} /$ year that is not explained by the normal channeling in infancy to adjust linear growth to target height trajectory [13], by the prepubertal growth dip or by pubertal delay) $[5,6]$. However, a diagnosis of GH deficiency (GHD) does not require a height cutoff, particularly in the context of very young children with hypoglycemia and/or midline defects/pathologies, or recently developed GHD.

Children with short stature may be evaluated inadequately in several situations. These include familial short stature (FSS), short stature in girls, and growth in childhood cancer survivors. FSS is generally considered a nor-

Diagnosis, Genetics, and Therapy of Short Stature in Children mal variant of growth due to a combination of polygenic and environmental effects. More recently, additional understanding of the genetic underpinnings of growth has raised the possibility that a short child who has a short parent may have an underlying genetic cause requiring evaluation. Short stature in girls has historically been underinvestigated, and it is now recommended that girls and boys be similarly evaluated [14]. Childhood cancer survivors represent a group in whom growth disorders are common. However, diagnosis may be delayed, particularly when height velocity is falsely reassuring because of early onset of puberty [15]. Pubertal status must also be considered in children who may have constitutional delay of growth, as they have a decline in height percentiles when other children are having a growth spurt. Additionally, due to the delay in puberty, height velocity can decrease to what could, in other circumstances, be considered abnormal. Interpretation of a child's height and height velocity based upon his/her pubertal status reduces misclassification of children with delayed puberty as having GHD [16].

All patients should have their head circumference measured, as this can point to specific genetic abnormalities. Patients (and their short parents) should be assessed for disproportion by measuring sitting height and arm span $[17,18]$. The use of sitting height/height ratio is believed to be more reliable and reproducible, and is preferred over upper/lower segment ratio when available. Patients should be assessed for dysmorphisms that may provide clues to the underlying diagnosis, such as a $\mathrm{SHOX}$ deficiency (mesomelia and Madelung deformity) or constitutive activation of FGFR3 (macrocephaly and lumbar hyperlordosis).

Laboratory tests should be guided by clinical features rather than routinely applied to all patients with short stature. Most textbooks and the previous GRS consensus on the topic of short stature [9] recommend routine laboratory screening for occult disease in asymptomatic short children, although one study has suggested that such screening has a low yield in short children with a height velocity $>5 \mathrm{~cm} /$ year, with the possible exception of celiac disease [19]. One aspect to take into consideration is that this study was conducted in a tertiary care center, and, consequently, many non-endocrine conditions may have already been investigated and ruled out by the primary care physician - hence the low yield in the pediatric endocrine clinic. Clinical discretion should be applied to the scope of testing for non-endocrine disease.

Bone age assessment can be useful in evaluating short stature, although its interpretation can be difficult. For 
instance, while the bone age is typically delayed in patients with GHD, making investigation for GHD unnecessary in a child with long-term short stature without a delayed bone age, this may not be the case in recently acquired GHD. Bone age is also less helpful in children with obesity, in whom the bone age is typically advanced, and in very young children ( $<2$ years old), in whom bone age assessment is less reliable. A hand and wrist radiograph performed to assess bone age may also be helpful in identifying subtle signs of skeletal dysplasia (e.g., mutations in genes encoding short stature homeobox [SHOX], fibroblast growth factor receptor-3 [FGFR3], natriuretic peptide 2 receptor [NPR2], and Indian hedgehog $[I H H]$ ) [2022 ]. Advanced bone age in a family with dominantly inherited short stature may suggest a mutation in the gene encoding aggrecan $[A C A N]$ [23]. Bone age may be advanced despite GHD in severe obesity, such as in patients with craniopharyngioma and hypothalamic hyperphagia [24]. New automated methods for bone age assessment are now available for clinical use in some countries [25], offering the opportunity for greater consistency in interpretation, but their use might increase the risk of missing radiological signs of skeletal dysplasia. Additionally, older bone age standards may not be applicable to all children. For example, the Greulich and Pyle standards (published in 1950) were derived from white children living in the United States and predominantly of North European ancestry $[9,26]$. Further work is needed on bone age assessment and prediction models for various ethnicities.

A skeletal survey is not appropriate as first-line evaluation, but it may be indicated in some individuals with a phenotype suggestive of skeletal dysplasia, including those with disproportionate short stature. One challenge is access to radiologists with expertise in the interpretation of skeletal surveys. The development of automated methods to recognize patterns of skeletal abnormalities consistent with various skeletal dysplasias would be beneficial.

\section{Testing for GHD}

The diagnosis of GHD remains a clinical one, where one synthesizes auxologic, anatomic, and laboratory data to arrive at a diagnosis. It should not be made based solely on laboratory testing.

\section{IGF-I/IGFBP-3}

IGF-I measurement should be undertaken using an assay with reliable reference data, with ranges based on age, gender, and pubertal status. Many factors contribute to the variability in assay results, including methodological factors and patient conditions such as malnutrition or undernutrition, chronic illness, and liver disease [27].

IGF-I values are an important component of the evaluation of a child with growth failure with low values being suggestive of a diagnosis of GHD. However, for children under the age of 3 years, the normal range of IGF-I values may include the lower limit of detection of the assay, and there is an overlap in values when comparing children with and without GHD. Thus, a low IGF-I in young children is difficult to interpret. An IGF-I level $>0$ SDS at any age makes GHD unlikely [28, 29]. IGF binding protein 3 (IGFBP-3) is considered a more reliable biomarker than IGF-I in children $<3$ years of age $[9,30]$ but is less sensitive than IGF-I after 3 years. A low IGFBP-3 in combination with a low IGF-I, while raising the likelihood of GHD, may also be found in other conditions, such as long-standing malnutrition and GH insensitivity, including genetic defects in GHR, STAT5B, and IGFALS [30, 31]. A low IGF-I associated with normal or elevated IGFBP-3 may be a sign of an IGF1 genetic defect [32].

Children with GHD may have delayed physical maturation, and, therefore, assessment of IGF-I must be interpreted in relation to pubertal status. IGF-I levels assessed in the context of pubertal status have the best positive predictive power for a diagnosis of GHD in peripubertal children [33]. Elevated IGF-I levels may be seen in patients with mutations in the IGF-I receptor (IGF1R) [34], IGF-I (IGF1) [35], or pappalysin 2 (PAPPA2) genes [36].

\section{Pituitary MRI in the Evaluation of GHD}

An MRI of the hypothalamus and pituitary gland should be performed in all patients diagnosed with GHD to detect anatomical defects of the hypothalamic-pituitary region, brain tumors, or other CNS disorders. This is important for predicting the likelihood of other pituitary deficiencies, the utility of genetic testing, and the likelihood of persistent GHD [37]. Further and repeated hormonal testing may be needed to assess other pituitary hormone deficiencies.

Cranial MRIs with a focus on the pituitary and hypothalamus are especially useful during the initial evaluation in newborns with midline defects, microphallus, and hypoglycemia. Beyond the newborn period, an MRI of the hypothalamus and pituitary should be ordered after confirming the diagnosis of GHD unless there is a high index of suspicion for a hypothalamic or pituitary lesion, such as complaints suggestive of neurologic abnormality associated with a low IGF-I level. MRI is not a test for establishing the diagnosis of GHD. If GHD has been excluded with biochemical tests, an MRI is typically not in- 
dicated. If there are focal neurological symptoms or signs suggestive of a mass lesion in the hypothalamic-pituitary region, the MRI should be considered earlier. If large sellar masses or certain pituitary defects (such as a hypoplastic pituitary gland, hypoplastic or absent stalk, or ectopic posterior pituitary) are present, formal GH provocation testing may be unnecessary when there are other clinical features indicating GHD. Depending on the imaging results, genetic testing for pituitary developmental defects may also be advisable. Pituitary size should be interpreted in the context of pubertal status, as the pituitary gland markedly increases in size during puberty $[37,38]$. The finding of a small pituitary gland by itself is not sufficient to make the diagnosis of GHD, but it may indicate the need for a more extensive evaluation of pituitary function. Findings on MRI that are most supportive of a diagnosis of GHD include absence of the anterior pituitary gland (empty sella), an ectopic posterior pituitary gland, and hypoplasia of the pituitary stalk and/or pituitary gland [39].

\section{Appropriate Clinical Settings for GH Stimulation/}

Provocative Tests

In neonates with a high pretest probability of GHD, a random $\mathrm{GH}$ level $<7 \mathrm{ng} / \mathrm{ml}$ in the first week of life supports this diagnosis [40]. A GH stimulation test is considered unnecessary in such neonates and also in infants with a combination of a history of hypoglycemia, hyperbilirubinemia, poor growth, midline defects [41], microphallus, low IGF-I and IGFBP-3, multiple pituitary hormone deficiencies, such as TSH and ACTH deficiency, and/or an abnormal cranial MRI (see above).

A GH stimulation test is not necessary when an alternative diagnosis for short stature is evident such as Turner syndrome, Noonan syndrome, Prader-Willi syndrome (PWS), aggrecan deficiency, SHOX deficiency, chronic renal insufficiency, Silver-Russell syndrome (SRS), or in children born small for gestational age (SGA) with unexplained persistent short stature. However, GH stimulation tests may be performed in these conditions when there is a suspicion of GHD in addition to the underlying condition based on disease-specific growth charts or very low IGF-I levels.

\section{Performance and Interpretation of GH Stimulation}

Tests

GH stimulation tests should be performed in the fasting state after adequate replacement of other hormone deficiencies (hypothyroidism and hypogonadism). Multiple GH secretagogues [9] have been used in GH stimu-

Diagnosis, Genetics, and Therapy of Short Stature in Children lation tests, but there are no data to demonstrate that one is better than another. GHRH is not appropriate for use as a stimulant in children as theoretically it will not diagnose GHD of hypothalamic or pituitary stalk origin. Stimulation tests in current use include the insulin tolerance test, and tests using glucagon, arginine, clonidine, L-dopa, and GH-releasing peptide-2 (GHRP2) [42]. Failure to respond to 2 provocative stimuli is needed to diagnose GHD, which limits false-positive results while not eliminating these completely. However, if there is a high index of suspicion, a single test may suffice. A sufficient $\mathrm{GH}$ response in one test rules out GHD in most cases. However, GHD may evolve over time, and therefore retesting may be considered at a later point of time in patients with conditions such as a history of cranial irradiation, optic nerve hypoplasia, traumatic brain injury, or certain genetic conditions. It is a matter of debate whether falsely normal results of GH stimulation tests may be seen in children with hypothalamic damage including cranial irradiation $[43,44]$. Peak GH levels following provocative testing correlate inversely with BMI, and thus may be low in children with obesity. The insulin tolerance test should be used with caution due to the risks associated with severe hypoglycemia.

Whether there is a spectrum of the degree of GHD remains controversial. Severe GHD is often defined as a peak GH level $<3 \mathrm{ng} / \mathrm{mL}$ on provocative testing in combination with a high prior likelihood of severe GHD based on clinical, laboratory, and imaging information. In some analyses, a peak $\mathrm{GH}$ level $<3 \mathrm{ng} / \mathrm{mL}$ was associated with higher height velocity in response to doses of recombinant human GH (rhGH) of $<0.3 \mathrm{mg} / \mathrm{kg} /$ week, while children whose peak GH level was $>3 \mathrm{ng} / \mathrm{ml}$ showed a height velocity that did not correlate with the peak $\mathrm{GH}$ following provocative testing [45]. However, other studies using higher rhGH doses have demonstrated a clear gradient of growth response, with an inverse correlation between peak $\mathrm{GH}(\leq 9 \mathrm{ng} / \mathrm{ml})$ and the height velocity in response to treatment [46].

There are no new data regarding the normal range for stimulated GH levels. However, it is important to note that GH assays, with the advent of monoclonal antibody testing and newer standards, produce $\mathrm{GH}$ measurements that are approximately $40 \%$ lower than those obtained using older immunoassay-based testing [47]. Therefore, the cutoffs for GH deficiency should be correspondingly reduced to minimize false-positive results (misclassifying as deficient a child with normal GH secretion). This change has already occurred in many countries, including Australia, New Zealand, Canada, most European coun- 
tries, and Japan. No exact threshold was agreed upon for a confirmatory diagnosis of GHD based on the present data, but the majority of delegates suggested that the threshold be revised to $7 \mathrm{ng} / \mathrm{mL}$, depending on the assay. Adjustment of this threshold should be determined by the pediatric endocrinology society specific to the country or region, and children previously diagnosed with GHD under different thresholds should not be required to be retested or denied continuation of therapy until attainment of appropriate adult height.

Furthermore, there are rare patients who appear to have true GHD even though their stimulated GH peak exceeds traditional cutoffs. The combination of other clinical data (e.g., significant short stature, poor height velocity, delayed bone age, very low IGF-I, and abnormal head MRI) can indicate GHD irrespective of the GH level, and these patients may require $\mathrm{GH}$ therapy for adequate growth [48]. Such patients may warrant initiation of rhGH therapy with annual reassessment based upon growth response. While obesity may blunt the peak $\mathrm{GH}$ response after stimulation, there are currently insufficient data to modify pediatric cutoffs based on body weight or BMI [49].

\section{Sex Steroid Hormone Priming as Part of Diagnostic}

Testing

Estrogen increases pituitary GH release. In children with an intact pituitary gland, existing data suggest that sex steroid priming increases GH secretion when development is earlier than Tanner stage III. Sex steroid priming may thus improve the specificity of the GH stimulation test $[50,51]$. However, such priming has not been standardized, the ideal age to recommend priming has not been defined, and data are lacking regarding the need to adjust the cutoff for a diagnosis of GHD in patients who undergo sex steroid priming. Thus, its efficacy in improving the diagnostic performance of $\mathrm{GH}$ provocation testing in general is unclear, with the exception of those with suspected constitutional delay in growth and puberty (CDGP). Use of this strategy has varied widely among centers and regions.

Supporters of sex steroid priming believe that this would reduce the number of children incorrectly diagnosed with GHD (false positives). Others agree that there is excessive diagnosis of GHD in children but do not believe that there are strong data that adding priming will necessarily improve the accuracy of this diagnosis. Currently, no clear consensus exists for the use of $\mathrm{GH}$ priming outside of adolescence when there is delayed puberty.

\section{Distinguishing CDGP from GHD}

It can be challenging to differentiate CDGP from GHD as in both conditions there is a height SDS deflection and relatively low height velocity compared with cross-sectional population references. The majority of patients diagnosed with GHD in the peripubertal period are ultimately found to have CDGP rather than isolated GHD. When evaluating an adolescent, one should take into account the relative decline in height velocity and GH secretion [52] that occurs with pubertal delay. Currently, this is inferred by extrapolating from prepubertal growth on established growth charts. We recommend the use of appropriate height velocity references [53] and the development of appropriate growth charts for adolescents with pubertal delay, as this would aid in confirming normal growth patterns [16, 54].

Before treating a prepubertal adolescent with short stature or growth deceleration, an evaluation of the $\mathrm{GH}$ axis should be considered. While there are controversies about using sex steroid priming as a general rule before $\mathrm{GH}$ provocation testing, there is overall consensus that this is one setting in which this is an appropriate approach. A normal GH stimulation test excludes GHD in this group.

Children at an age when CDGP is typically diagnosed have a low risk of GHD unless it is an acquired form of GHD. However, when auxological phenotype and family history are not definitive, it is recommended to screen for GHD with IGF-I levels using appropriate references for pubertal stages [32]. If the diagnosis has been made in this setting and the pituitary MRI is normal, the diagnosis of GHD should be reconsidered, particularly following completion of statural growth [9].

\section{Application of Genetic Testing for the Evaluation of a Child with Short Stature}

Genomic technology continues to advance and is being applied in multiple clinical settings [55]. A growing number of genetic causes of short stature affecting the growth plate and the pituitary-IGF axis are now recognized [3, 56-58]. Making the diagnosis of a genetic condition may help predict the response to GH therapy. A glossary of related terms is shown in Table 1; Table 2 depicts the importance of identifying a genetic cause for short stature.

There was consensus that genetic and/or epigenetic testing is not required for all children with short stature, but that it should be utilized in the diagnostic assessment of specific groups of children whose phenotype suggests a high likelihood of a genetic cause. These include severe 
Table 1. Glossary

Whole genome sequencing (WGS)

Technique in which essentially the entire genome ( $\sim 3$ billion base pairs) is sequenced. This includes noncoding regions such as introns that regulate gene expression.

Whole exome sequencing (WES)

Technique in which the exons (protein-coding portion of the genes) of all $\sim 20,000$ protein-coding genes are sequenced. This represents approximately $2 \%$ of the whole genome but is thought to include the majority of disease-causing mutations.

Single nucleotides polymorphism (SNP) array

A microarray chip which genotypes common SNPs across the entire genome. There are typically hundreds of thousands of SNP probes on each microarray chip. This array allows one to identify genomic deletions or duplications which can lead to growth disorders (often syndromic), as well as most forms of uniparental disomy (UPD).

Comparative genomic hybridization (CGH) array

Provides similar results as the SNP array except that UPDs are not detected.

\section{DNA Methylation}

An epigenetic modification of DNA in which methyl groups are added to specific nucleotides of the DNA. Methylation is found throughout the genome and typically suppresses gene transcription. Defects in methylation can cause growth disorders and are implicated in the regulation of imprinted genes (genes in which only one copy is expressed, depending on which parent it is inherited from).

familial forms of isolated GHD or specific syndromic forms of multiple pituitary hormone deficiencies, severe short stature $(<-3$ SDS for the population or $>3$ SD lower than mid-parental target height), body disproportion and/or skeletal dysplasia, and SGA who did not present adequate catch-up growth $[18,59,60]$. Patients with syndromic short stature represent a complex group that may warrant referral for multidisciplinary assessment at a specialized growth center with expertise in genetic diagnosis and with genetic counselors available.

A genetic cause is more likely to be identified where there is familial segregation with an autosomal dominant or recessive pattern or with a history of consanguinity. Specific phenotypes can also point to specific genetic causes (e.g., advanced bone age and family history of early arthritis suggest an ACAN mutation).

Genetic test selection can be directed by a thorough phenotype assessment $[2,58]$. The development of clinical scoring systems [61], including laboratory data, to guide clinicians to appropriate testing panels would be helpful.

Diagnosis, Genetics, and Therapy of Short Stature in Children
Table 2. Importance of identification of a genetic cause for short stature

- Guide growth hormone treatment of some patients

- Provide prognostic information

- Facilitate surveillance for other associated conditions that may require treatment

- In rare cases, a genetic diagnosis may identify a disorder in which growth therapy is contraindicated (e.g., the Bloom syndrome)

- A genetic diagnosis can provide peace of mind for the patient and caregivers by ending the diagnostic odyssey

- Prompt genetic counseling for future offspring and family members

- Prompt identification of additional family members

- Inform pharmacogenomics in the future (this has not yet been demonstrated)

In girls with short stature, a karyotype should be performed [62] due to the possibility of Turner syndrome. If karyotype is $46, \mathrm{XX}$ and there is a strong clinical suspicion of Turner syndrome, a microarray or fluorescence in situ hybridization can be considered, preferably in a different cell type than blood cells (e.g., buccal smear or cells in urine). In girls without such suspicion, a SNP array has a better diagnostic yield because it can detect copy number variants (microdeletions and microduplications), as well as most forms of uniparental disomy, while its sensitivity for detecting Turner syndrome is equivalent to that of conventional karyotyping [63].

Subsequent genetic tests should be guided by phenotypic data, but increasingly the candidate gene approach is being replaced by a hypothesis-free approach using an SNP array, followed by a growth-specific whole exome sequencing-based gene panel. Whole exome sequencing should be focused on children with the most severe short stature ( $<-3$ SDS from population or from mid-parental target height) and those with syndromic features. If genetic tests reveal no abnormality, a methylation analysis may be ordered (especially for SGA children) to identify methylation disorders including SRS and Temple syndrome [61]. In short children born SGA and short children born following assisted reproductive technologies, methylation studies may be indicated in the initial diagnostic evaluation depending upon the phenotype. Importantly, findings on methylation analysis may not be identified by other nonspecific molecular technologies such as SNP array, or whole genome or exome sequencing.

The identification of pathogenic genetic variants can be difficult [64]. Some variations (such as frameshift mutations) are obviously pathogenic, but others require ad- 
ditional data for interpretation, including functional studies. When the genetic variant is rare or novel, incorporating phenotype/genotype correlation and familial segregation is critical in the interpretation of pathogenicity. Interpretation of rare or new variants should follow the current recommendations and may require collaborative input from growth experts and/or geneticists [64].

There are limitations in reporting novel or rare variants of uncertain significance. Clinicians must understand the limitations of the clinical laboratory report [65]. To this end, information about new genetic technologies and the interpretation of results from these genetic tests should be included in the training of pediatric endocrinologists.

\section{Guidelines for Treating Children with rhGH}

The goal of treatment of children with GHD is to replace the deficient GH for growth, metabolism, and wellbeing. The starting dose of rhGH and dose adjustments are mainly based on weight or body surface area and growth response [66].

\section{rhGH Starting Doses}

The dose of rhGH should be individualized according to $\mathrm{GH}$ responsiveness aiming for the lowest effective dose, i.e., the lowest dose at which there is an appropriate response in height velocity. This needs to be in harmony with local guidelines using doses that are within the indications of the various products and not limited by individual product labeling. Depending on the country, current regulatory recommendations vary for $\mathrm{rhGH}$ dosing. For example, for GHD, the starting dose is $25 \mu \mathrm{g} / \mathrm{kg} / \mathrm{day}$ $(0.18 \mathrm{mg} / \mathrm{kg} /$ week) in most countries in Europe, Canada, and Japan, very similar in Australia $\left(4.5 \mathrm{mg} / \mathrm{m}^{2} /\right.$ week), and up to $43 \mu \mathrm{g} / \mathrm{kg} /$ day in the USA $(0.3 \mathrm{mg} / \mathrm{kg} /$ week). The initial dose of rhGH therapy for GHD should be guided by the severity of GHD. Patients with more severe GHD, as evidenced by lower peak GH levels, lower IGF-I levels, and clinical features (such as the severity of the growth deficit, bone age delay, presence of additional pituitary deficiencies, anatomical abnormalities on brain MRI, or genetic defects associated with GHD), should be initially treated with lower doses of rhGH. In such cases, a dose of $17-35 \mu \mathrm{g} / \mathrm{kg} /$ day $(0.16-0.24 \mathrm{mg} / \mathrm{kg} /$ week $)$, roughly equivalent to $0.7-1.0 \mathrm{mg} / \mathrm{m}^{2}$ body surface area/day $(5-7 \mathrm{mg} /$ $\mathrm{m}^{2} /$ week) $[67,68]$, may suffice for catch-up growth and attainment of a normal adult height.

For other approved, non-GHD indications, the doses prescribed may need to be higher. We recommend start- ing rhGH at the approved dose ranges, possibly using prediction models [69] to aid in dose optimization. In certain conditions, such as with older SGA patients and in the late diagnosis of Turner syndrome, it is recommended that rhGH be started at a dose that is at the higher end of the approved range. In infants and adolescents, patients with obesity and those with PWS, rhGH dosing may be based on body surface area rather than weight [70].

\section{rhGH Dose Adjustments}

The main goal of rhGH treatment is to increase height velocity and adult height. Consequently, the principal parameter to adjust rhGH should be the growth response. The appropriateness of the rhGH dose should be assessed based on height velocity and change in height SDS every 6-12 months. The use of IGF-I serum levels may provide additional information about treatment efficacy, adherence, and, theoretically, safety. Prediction models can also be used to guide rhGH dosing $[69,71-73]$. These models should be further validated in prospective studies. Prediction algorithms suggest that in most disorders the first-year response to a rhGH dose is one of the most important predictive variables for adult height, and the lowest dose necessary to optimize height velocity should be used in all indications for rhGH treatment.

Measurement of IGF-I levels should be considered annually but may be done more frequently (e.g., after a dose adjustment) or to monitor compliance. It may also provide earlier information regarding response to $\mathrm{rhGH}$ than change in height velocity. Some trials that used IGF-Ibased rhGH dosing suggest that this strategy may optimize therapy in GHD and idiopathic short stature (ISS) $[46,74]$ while allowing for use of smaller doses [75]. When using IGF-I levels to adjust dose, the "ideal" level of IGF-I should, in general, be close to 0 SDS in GHD, but individual adjustments are typically necessary based on auxological measurements. For example, children with severe GHD may respond very well to rhGH doses that result in IGF-I levels below 0 SDS. A 20\% rhGH dose adjustment usually leads to a 1 SDS change in IGF-I concentration in GHD patients [76]. Once catch-up growth is achieved in patients with GHD, consideration can be given to reducing the rhGH dose with close monitoring for continued normal height velocity [77].

In non-GHD conditions, such as ISS, IGF-I levels of approximately +1 SDS or higher are usual, but the target should be adjusted on an individual basis based on auxological measurements. When consecutive IGF-I levels are above +2 SDS, consideration should be given to reducing the rhGH dose to achieve long-term IGF-I levels in the 
normal range, unless IGF-I insensitivity is likely. In certain conditions characterized by partial IGF-I insensitivity (such as SRS/SGA [61], PWS [78], and IGF-IR defects [34]), IGF-I levels above + 2 SDS may be needed for effective growth. This is also true in some children with Turner syndrome [79]. In children, no upper limit of IGF-I has been demonstrated to be associated with rhGH-treatment-related safety issues [80], although long-term data are lacking. It may be important to counsel patients and caregivers about this dosing strategy, particularly when high IGF-I levels are targeted.

Low levels of IGF-I may indicate poor adherence, inadequate storage, or the presence of another condition affecting GH response. High IGF-I levels may reflect some degree of IGF-I insensitivity, especially if associated with poor growth response.

There is no compelling evidence to support the use of IGFBP-3, free IGF-I, acid-labile subunit levels, or the IGF-I/IGFBP-3 ratio in monitoring rhGH therapy. In patients with GHD and syndromes that increase cancer risk, including cancer survivors, an IGF-I target that is not above the mean may be preferred [81]. However, this remains theoretical, as there is no evidence that such a goal reduces the risk of cancer recurrence or second malignancy.

\section{Definition and Management of Suboptimal Response to $r h G H$}

An inadequate response after initiation of rhGH therapy in patients with GHD is often defined by one or more of the following criteria: $\Delta$ height velocity $<2 \mathrm{~cm} /$ year, height velocity $\operatorname{SDS}<0$, or $\Delta$ height $S D S<0.3 /$ year during the first 6-12 months of therapy [82], but there is considerable variation in response according to age and pubertal maturation. Clinicians should use age, sex, and etiologyspecific (including for GHD) response charts to assess individual growth responses after starting rhGH therapy $[83,84]$. This is particularly important for genetic syndromes. During adolescence, adequacy of growth response should also be judged according to pubertal status. In addition, prediction models can aid in assessing inadequate low initial responses, and the rhGH dose being used should be taken into consideration [69]. Cancer survivors who have received radiation to the spine or growth plates (e.g., total body irradiation) have a relatively low growth response [15] and may present disproportionate growth mainly due to spinal irradiation. For genetic syndromes, standard growth charts should not be used for reference, and disease-specific growth charts should be utilized when available.

Diagnosis, Genetics, and Therapy of Short Stature in Children
When a suboptimal growth response for pubertal status is noted, a review of adherence and injection techniques is indicated. IGF-I levels can be used as a measure of adherence and help identify GH or IGF-I resistance conditions [4]. Re-evaluation of other etiologies of growth faltering should be performed even after a diagnosis of GHD or other conditions, as the onset of scoliosis and chronic illnesses (in particular, celiac disease and inflammatory bowel disease), hypothyroidism, inadequate nutrition, medications that impair growth, and challenges in the psychosocial environment may inhibit the response to GH. Additional diagnoses such as skeletal dysplasia and other genetic conditions should be considered. In rare cases of whole GH1 deletions, the presence of neutralizing anti-GH antibodies should be assessed. If none of these conditions is present, and IGF-I levels are below the target range, the rhGH dose can be increased to determine whether height velocity and the IGF-I level increases. rhGH should be discontinued if suboptimal response persists.

\section{Alternative Treatments for Children with Suboptimal Response to rhGH}

Alternative therapies may be considered for particular situations identified in patients with inadequate growth response. These may include nutritional and other interventions. Although uncommon, lack of responsiveness to rhGH may be due to genetic forms of GH insensitivity; these patients may respond to rhIGF-I. Alternative therapy in the form of aromatase inhibitors in pubertal boys directed at delaying epiphyseal fusion could be considered, but this remains controversial [85] and off-label. The use of GnRH analogues to delay epiphyseal closure as a single agent to augment adult height is not indicated [86], but adding a GnRH analogue to rhGH therapy may be considered for children with GHD or SGA and/or SRS patients if height SDS is low at pubertal onset $[87,88]$. This should be discussed in a personalized approach to treatment in centers of reference or in a pharmaceutical trial as this is off-label.

\section{Safety of rhGH in Children}

Side effects caused by rhGH therapy are uncommon, and there is a paucity of data linking the rhGH dose to treatment-related adverse events in children. In addition, there is no upper limit of IGF-I that has been associated with treatment-related safety issues, although long-term data are currently lacking [89]. There are some genetic conditions, such as Turner syndrome, that are associated with an increased risk for adverse events, as detailed in the GRS Growth Hormone Safety Workshop Position Paper [89].

Horm Res Paediatr 2019;92:1-14

DOI: $10.1159 / 000502231$ 


\section{Recent Developments}

\section{New Diagnostic Tests}

Macimorelin, a ghrelin agonist that provokes GH release from the pituitary [90], was recently approved as a diagnostic test for GHD in adults in the USA and Europe. Advantages of this stimulant include oral administration, the requirement for fewer blood samples over a shorter period of time, the presence of fewer side effects than most other provocative agents, high sensitivity and specificity, and greater reproducibility than other stimuli [89]. There are no published data using this agent in children.

It is important to recognize that there are several differences between children and adults in testing for GHD. Most adults have acquired structural pituitary abnormalities and very low $\mathrm{GH}$ responses to stimulation testing, while some children are speculated to have congenital hypothalamic dysfunction, and the response of such patients to a ghrelin agonist is unknown. Additionally, children have a broader range of peak $\mathrm{GH}$ responses to provocative testing. The use of GH secretagogues as diagnostic tests in children may, therefore, fail to identify children with hypothalamic dysfunction.

GHRP2 is an intravenous GH secretagogue used in Japan with the advantage of stimulating ACTH release and the potential ability to assess the hypothalamic-pituitaryadrenal and GH axes simultaneously $[42,91,92]$.

\section{New Growth-Promoting Agents \\ Long-Acting GH}

Several pharmaceutical companies have developed $\mathrm{GH}$ compounds with a longer duration of action than daily rhGH, and compounds are available for commercial use in China and Korea. These drugs can be administered weekly or even less frequently, which may improve adherence. They are currently being studied in pediatric and adult populations. As every long-acting GH molecule will be a new biologic entity, establishing the ideal timing of IGF-I measurement and the recommended ranges of IGF-I levels will be important for each agent. Understanding when to measure IGF-I will be key to individualizing drug doses for patients. Pharmacodynamic models of expected IGF-I levels across the duration of action will be helpful in guiding dose adjustment for each product. Long-term postmarketing longitudinal studies for safety surveillance that extend beyond the treatment period have been recommended for all approved compounds [81].
Oral Ghrelin Analogues under Consideration

Oral ghrelin analogues (such as LUM-201/MK677) are unlikely to be useful in children with severe pituitary forms of GHD but may have potential in children with hypothalamic GHD or milder degrees of pituitary dysfunction. They may also be effective in non-GHD children with low BMI, such as SGA, ISS, SRS, and Noonan syndrome given their orexigenic effects.

\section{C-Natriuretic Peptide Analogues}

C-natriuretic peptide (CNP) is expressed in the growth plate and is an important regulator of chondrocyte proliferation and differentiation, acting through the CNP receptor NPR2. CNP analogues (such as BMN111 and TransCon CNP) bind to NPR2, interfere with the downstream FGFR3 signaling cascade, and are under investigation in achondroplasia [93]. FGFR3 is mutated and constitutively active in achondroplasia, hypochondroplasia, and associated disorders. CNP analogues may be theoretically useful in hypochondroplasia, CNP deficiency, heterozygous NPR2 mutations, other skeletal dysplasias, and ISS.

\section{Future Directions}

Further research is clearly required in a number of areas related to the diagnosis and treatment of children and adolescents with short stature, with the following topics considered high priority by the expert group.

1. International standardization/harmonization of $\mathrm{GH}$ and IGF-I assays, as assay variability can impact these measurements.

2. Guidance regarding the ideal GH stimulation test, including evaluation of newer agents such as macimorelin.

3. Standardization of GH stimulation testing procedures.

4. Establishment of diagnostic cutoffs for GHD at different pubertal stages.

5. Investigation of the impact of obesity on the diagnosis of GHD in children.

6. Assessment of accurate and appropriate tests to diagnose persistent GHD during the transition years between childhood and adulthood.

7. Exploration of the metabolomic signature in children with GHD before and after rhGH therapy as this may reveal new biomarkers for diagnosis and efficacy of treatment.

8. To continue to unravel the many genetic and epigenetic factors that contribute to stature and response to growth promoting therapies.
Collett-Solberg et al. 
9. Establishment of international registries providing phenotype and genotype data on rarer genetic causes of short stature; this could assist in establishing new diagnostic and treatment strategies and facilitate a personalized approach to the evaluation and treatment of children with growth disorders.

\section{Acknowledgments}

The GRS and all the authors of this report would like to thank the following Workshop participants from regulatory agencies and industry for their invaluable and unrestricted sponsorship, comments, and perspectives. From regulatory agencies: Kolbeinn Guðmundsson (EMA) and Marina Zemskova (FDA), and from industry: Nicola Ammer (Æterna Zentaris), Jonathan Day (BioMarin Pharmaceutical Inc.), Roy Gomez (Pfizer), Rick Hawkins (Lumos Pharma), Michael Højby (Novo Nordisk A/S), Lei Jin (GeneScience Pharmaceutical), Roberta Luzzi (Sandoz Biopharmaceuticals), Rudolf Schemer (Immunodiagnostic Systems - IDS), and Aimee Shu (Ascendis Pharma A/S).

Judith Andersen is thanked for her undaunted assistance in arranging the Workshop.

\section{Statement of Ethics}

This publication about a meeting held with scientific and regulatory experts to review published data is exempt from ethics committee approval.

\section{Disclosure Statement}

G.A., M.B., P.T.C., C.G., Y.H., P.L.H., R.H., V.K., and X.L. have no conflicts of interest to declare; P.F.B. was a consultant for Novo Nordisk and received research funding from Novo Nordisk, Ipsen, and Opko; B.M.K.B. was a principal investigator of research grants to the Massachusetts General Hospital from Novo Nordisk and Opko, and a recipient of consulting honoraria from Merck Serono, Novo Nordisk, Pfizer, and Strongbridge; M.C.S.B. received speaker fees from Pfizer; C.S.Y.C. is an investigator for studies funded by Opko and Merck Serono; L.E.C. is an investigator for studies funded by Ascendis and Opko; P.C. was a consultant for Ascendis, Genexine, GenSci, and Opko; P.F.C.-S. received travel grants and speaker fees from Pfizer, Merck-Serono, Novo Nordisk, and Sandoz; A.D. was a consultant for Opko Biologics, Novo Nordisk, Pfizer, and Ipsen, and received research funding from Novo Nordisk and Ipsen and holds a patent for the use of recombinant PAPPA2 as a growth promoting therapy; C.L.D. served on the GeNeSIS International Advisory Board (Lilly) and as an ad hoc consultant for Lilly, EMD Serono/Merck, Hoffman LaRoche, Sandoz, Pfizer, Versartis, Opko, and Lumos, received speaker fees from Lilly, EMD Serono/Merck, Hoffman LaRoche, Sandoz, Pfizer, and Novo Nordisk, and research support from Lilly, EMD Serono, Hoffman LaRoche, Pfizer, Sandoz, Versartis, and Opko. A.R.H. acts as consultant for Ascendis, Genexine, and
Novo Nordisk; A.A.L.J. received speaker fees from Sandoz; A.J. is the principal investigator of a multicenter study on effects of GH in short SGA children (North European Small for Gestational Age Study, NESGAS) which received unrestricted financial support from Novo Nordisk, received speaker fees from Sandoz, Ipsen, Novo Nordisk, and Merck; P.K. received a grant from Novartis and was a consultant for Ipsen; J.J.K. was a consultant for Sandoz and Merck KGaA and received speaker fees from Pfizer; B.K. received speaker fees from Merck Darmstadt, Novo Nordisk, Pfizer, Sandoz, and GeneScience Pharmaceuticals, was an investigator for the PATRO observational study (Sandoz), and participated in the Pfizer iGRO board; M.L.A.L. received travel grants from several Pharmaceutical Companies; B.S.M. was a consultant for Abbvie, Ascendis, BioMarin, Bluebird Bio, Novo Nordisk, Pfizer, Sandoz, Sanofi Genzyme, and Tolmar, and has received research support from Alexion, Abbvie, Amgen, Ascendis, BioMarin, Novo Nordisk, Opko, Protalix, Sandoz, Sangamo, Sanofi Genzyme, Tolmar, and Takeda; M.M. was a consultant for Sanofi; co-investigator on an investigator-initiated grant from Novo Nordisk; and received grant funding from NICHD, NIDDK, and NIMH; I.N. received speaker fees from Sandoz and Merck Serono, and research support from Merck Serono and Pfizer; S.R. was a consultant for Ascendis Pharma and CVS-Caremark; M.B.R. received speaker fees from Sandoz, Merck, Mediagnost, and Pfizer; A.D.R. was a consultant to Acerus Pharma, AYTU BioScience, Clarus Pharmaceuticals, Inc, United States Anti-Doping Agency (USADA), and Ultragenyx Pharmaceutics; R.G.R. was a consultant for BioMarin, Opko, Genexine, Ascendis, Lumos, and Æterna Zentaris; P.S. was an investigator for Ascendis, Opko, and Novo Nordisk, and a consultant for Genexine; J.M.W. is member of advisory boards of Opko, Merck, Ammonett, Æterna Zentaris, Agios, and BioMarin, and received speaker fees from Pfizer, Versartis, Sandoz, Lilly, Novo Nordisk, JCR, Merck, and Ipsen; J.W. received research support from Pfizer and Ipsen, speaker fees from Ipsen, Novo Nordisk, Merck, Hexal, and Pfizer, and has attended scientific advisory boards for Ipsen, Novo Nordisk, and Ferring.

\section{Funding Sources}

The workshop was supported, in part, by unrestricted educational grants from Æterna Zentaris, BioMarin, Ascendis, Chiasma, Ferring, GeneScience, IDS, Ipsen, Lumos, Merck, Novo Nordisk, Pfizer, Sandoz, and Strongbridge.

References

1 Growth Hormone Research Society; GH Research Society. Consensus guidelines for the diagnosis and treatment of growth hormone (GH) deficiency in childhood and adolescence: summary statement of the GH Research Society. J Clin Endocrinol Metab. 2000 Nov; 85(11):3990-3.

2 Collett-Solberg PF, Jorge AA, Boguszewski MC, Miller BS, Choong CS, Cohen P, et al. Growth hormone therapy in children; research and practice - A review. Growth Horm IGF Res. 2019 Feb;44:20-32. 
3 Baron J, Sävendahl L, De Luca F, Dauber A, Phillip M, Wit JM, et al. Short and tall stature: a new paradigm emerges. Nat Rev Endocrinol. 2015 Dec;11(12):735-46.

4 Johannsson G, Bidlingmaier M, Biller BM, Boguszewski M, Casanueva FF, Chanson P, et al.; Growth Hormone Research Society. Growth Hormone Research Society perspective on biomarkers of $\mathrm{GH}$ action in children and adults. Endocr Connect. 2018 Mar; 7(3):R126-34.

5 Grote FK, van Dommelen P, Oostdijk W, de Muinck Keizer-Schrama SM, Verkerk PH, Wit JM, et al. Developing evidence-based guidelines for referral for short stature. Arch Dis Child. 2008 Mar;93(3):212-7.

6 Saari A, Sankilampi U, Hannila ML, Saha MT, Mäkitie O, Dunkel L. Screening of turner syndrome with novel auxological criteria facilitates early diagnosis. J Clin Endocrinol Metab. 2012 Nov;97(11):E2125-32.

7 Wehkalampi K, Vangonen K, Laine T, Dunkel L. Progressive reduction of relative height in childhood predicts adult stature below target height in boys with constitutional delay of growth and puberty. Horm Res. 2007;68(2): 99-104.

8 WHO Multicentre Growth Reference Study Group. WHO Child Growth Standards based on length/height, weight and age. Acta Paediatr Suppl. 2006 Apr;450:76-85.

9 Cohen P, Rogol AD, Deal CL, Saenger P, Reiter EO, Ross JL, et al.; 2007 ISS Consensus Workshop participants. Consensus statement on the diagnosis and treatment of children with idiopathic short stature: a summary of the Growth Hormone Research Society, the Lawson Wilkins Pediatric Endocrine Society, and the European Society for Paediatric Endocrinology Workshop. J Clin Endocrinol Metab. 2008 Nov;93(11):4210-7.

10 Oostdijk W, Grote FK, de Muinck KeizerSchrama SM, Wit JM. Diagnostic approach in children with short stature. Horm Res. 2009; 72(4):206-17.

11 Hermanussen M, Cole J. The calculation of target height reconsidered. Horm Res. 2003; 59(4):180-3.

12 Tanner JM, Goldstein H, Whitehouse RH. Standards for Children's Height at Age 2 to 9 years allowing for height of Parents. Arch Dis Child. 1970 Dec;45(244):819.

13 Karlberg J, Lawrence C, Albertsson-Wikland K. Prediction of final height in short, normal and tall children. Acta Paediatr Suppl. 1994 Dec;406 s406:3-9.

14 Grimberg A, Feemster KA, Pati S, Ramos M, Grundmeier R, Cucchiara AJ, et al. Medically underserved girls receive less evaluation for short stature. Pediatrics. 2011 Apr;127(4): 696-702.

15 Sklar CA, Antal Z, Chemaitilly W, Cohen LE, Follin C, Meacham LR, et al. HypothalamicPituitary and Growth Disorders in Survivors of Childhood Cancer: An Endocrine Society Clinical Practice Guideline. J Clin Endocrinol Metab. 2018 Aug;103(8):2761-84.
16 Addo OY, Sarafoglou K, Miller BS. Effect of Adjusting for Tanner Stage Age on Prevalence of Short and Tall Stature of Youths in the United States. J Pediatr. 2018 Oct;201:9399.e4.

17 Fredriks AM, van Buuren S, van Heel WJ, Dijkman-Neerincx RH, Verloove-Vanhorick SP, Wit JM. Nationwide age references for sitting height, leg length, and sitting height/ height ratio, and their diagnostic value for disproportionate growth disorders. Arch Dis Child. 2005 Aug;90(8):807-12.

18 Malaquias AC, Scalco RC, Fontenele EG, Costalonga $\mathrm{EF}, \mathrm{Baldin} \mathrm{AD}, \mathrm{Braz} \mathrm{AF}$, et al. The sitting height/height ratio for age in healthy and short individuals and its potential role in selecting short children for SHOX analysis. Horm Res Paediatr. 2013;80(6):449-56.

19 Sisley S, Trujillo MV, Khoury J, Backeljauw P. Low incidence of pathology detection and high cost of screening in the evaluation of asymptomatic short children. J Pediatr. 2013 Oct;163(4):1045-51.

20 Hisado-Oliva A, Garre-Vázquez AI, Santaolalla-Caballero F, Belinchón A, Barreda-Bonis AC, Vasques GA, et al. Heterozygous NPR2 mutations cause disproportionate short stature, similar to Léri-Weill dyschondrosteosis. J Clin Endocrinol Metab. 2015 Aug; 100(8):E1133-42.

21 Binder G, Renz A, Martinez A, Keselman A, Hesse V, Riedl SW, et al. SHOX haploinsufficiency and Leri-Weill dyschondrosteosis: prevalence and growth failure in relation to mutation, sex, and degree of wrist deformity. J Clin Endocrinol Metab. 2004 Sep;89(9): 4403-8.

22 Vasques GA, Funari MF, Ferreira FM, AzaCarmona M, Sentchordi-Montané L, Barraza-García J, et al. IHH gene mutations causing short stature with nonspecific skeletal abnormalities and response to growth hormone therapy. J Clin Endocrinol Metab. 2018 Feb; 103(2):604-14.

23 Nilsson O, Guo MH, Dunbar N, Popovic J, Flynn D, Jacobsen C, et al. Short stature, accelerated bone maturation, and early growth cessation due to heterozygous aggrecan mutations. J Clin Endocrinol Metab. 2014 Aug; 99(8):E1510-8.

24 Geffner M, Lundberg M, KoltowskaHäggström M, Abs R, Verhelst J, Erfurth EM, et al. Changes in height, weight, and body mass index in children with craniopharyngioma after three years of growth hormone therapy: analysis of KIGS (Pfizer International Growth Database). J Clin Endocrinol Metab. 2004 Nov;89(11):5435-40.

25 Thodberg HH. Clinical review: an automated method for determination of bone age. J Clin Endocrinol Metab. 2009 Jul;94(7):2239-44.

26 Pyle SI, Waterhouse AM, Greulich WW. Attributes of the radiographic standard of reference for the National Health Examination Survey. Am J Phys Anthropol. 1971 Nov; 35(3):331-7.
27 Clemmons DR. Consensus statement on the standardization and evaluation of growth hormone and insulin-like growth factor assays. Clin Chem. 2011 Apr;57(4):555-9.

28 Blum WF, Alherbish A, Alsagheir A, El Awwa A, Kaplan W, Koledova E, et al. The growth hormone-insulin-like growth factor-I axis in the diagnosis and treatment of growth disorders. Endocr Connect. 2018 Jun;7(6):R212-22.

29 Bidlingmaier M, Friedrich N, Emeny RT, Spranger J, Wolthers OD, Roswall J, et al. Reference intervals for insulin-like growth factor-1 (igf-i) from birth to senescence: results from a multicenter study using a new automated chemiluminescence IGF-I immunoassay conforming to recent international recommendations. J Clin Endocrinol Metab. 2014 May;99(5):1712-21.

30 Büscher AK, Büscher R, Pridzun L, Langkamp M, Wachendorfer N, Hoyer PF, et al. Functional and total IGFBP3 for the assessment of disorders of the GH/IGF1 axis in children with chronic kidney disease, GH deficiency, or short stature after SGA status at birth. Eur J Endocrinol. 2012 May; 166(5): 923-31.

31 Shen Y, Zhang J, Zhao Y, Yan Y, Liu Y, Cai J. Diagnostic value of serum IGF-1 and IGFBP-3 in growth hormone deficiency: a systematic review with meta-analysis. Eur J Pediatr. 2015 Apr;174(4):419-27.

32 Finken MJ, van der Steen M, Smeets CC, Walenkamp MJ, de Bruin C, Hokken-Koelega AC, et al. Children Born Small for Gestational Age: Differential Diagnosis, Molecular Genetic Evaluation, and Implications. Endocr Rev. 2018 Dec;39(6):851-94

33 Inoue-Lima TH, Vasques GA, Scalco RC, Nakaguma M, Mendonca BB, Arnhold IJ, et al. IGF-1 assessed by pubertal status has the best positive predictive power for $\mathrm{GH}$ deficiency diagnosis in peripubertal children. J Pediatr Endocrinol Metab. 2019 Feb;32(2):173-9.

34 Walenkamp MJE, Robers JML, Wit JM, Zandwijken GRJ, van Duyvenvoorde HA, Oostdijk W, et al. Phenotypic features and response to growth hormone treatment of patients with a molecular defect of the IGF-1 receptor. J Clin Endocrinol Metab. 2019 Aug; 104(8):3157-71.

35 Netchine I, Azzi S, Houang M, Seurin D, Perin L, Ricort JM, et al. Partial primary deficiency of insulin-like growth factor (IGF)-I activity associated with IGF1 mutation demonstrates its critical role in growth and brain development. J Clin Endocrinol Metab. 2009 Oct;94(10):3913-21.

36 Andrew M, Liao L, Fujimoto M, Khoury J, Hwa V, Dauber A. PAPPA2 as a therapeutic modulator of IGF-I bioavailability: in vivo and in vitro evidence. J Endocr Soc. 2018 May; 2(7):646-56.

37 Maghnie M, Rossi A, di Iorgi N, Gastaldi R, Tortori-Donati P, Lorini R. Hypothalamicpituitary magnetic resonance imaging in growth hormone deficiency. Expert Rev Endocrinol Metab. 2006 May;1(3):413-23. 
38 Fink AM, Vidmar S, Kumbla S, Pedreira CC, Kanumakala S, Williams C, et al. Age-related pituitary volumes in prepubertal children with normal endocrine function: volumetric magnetic resonance data. J Clin Endocrinol Metab. 2005 Jun;90(6):3274-8.

39 Kalina MA, Kalina-Faska B, Gruszczyńska K, Baron J, Małecka-Tendera E. Usefulness of magnetic resonance findings of the hypothalamic-pituitary region in the management of short children with growth hormone deficiency: evidence from a longitudinal study. Childs Nerv Syst. 2012 Jan;28(1):121-7.

40 Binder G, Weidenkeller M, Blumenstock G, Langkamp M, Weber K, Franz AR. Rational approach to the diagnosis of severe growth hormone deficiency in the newborn. J Clin Endocrinol Metab. 2010 May;95(5):2219-26.

41 Pampanini V, Pedicelli S, Gubinelli J, Scirè G, Cappa M, Boscherini B, et al. Brain Magnetic Resonance Imaging as First-Line Investigation for Growth Hormone Deficiency Diagnosis in Early Childhood. Horm Res Paediatr. 2015;84(5):323-30.

42 Hayakawa T, Kitamura T, Tamada D, Mukai K, Hayashi R, Takahara M, et al. Evaluation of hypothalamic-pituitary-adrenal axis by the GHRP2 test: comparison with the insulin tolerance test. J Endocr Soc. 2018 Jun;2(8): $860-9$.

43 Darzy KH, Aimaretti G, Wieringa G, Gattamaneni HR, Ghigo E, Shalet SM. The usefulness of the combined growth hormone (GH)releasing hormone and arginine stimulation test in the diagnosis of radiation-induced GH deficiency is dependent on the post-irradiation time interval. J Clin Endocrinol Metab. 2003 Jan;88(1):95-102.

44 Lissett CA, Saleem S, Rahim A, Brennan BM, Shalet SM. The impact of irradiation on growth hormone responsiveness to provocative agents is stimulus dependent: results in 161 individuals with radiation damage to the somatotropic axis. J Clin Endocrinol Metab. $2001 \mathrm{Feb} ; 86(2): 663-8$.

45 Bright GM, Julius JR, Lima J, Blethen SL. Growth hormone stimulation test results as predictors of recombinant human growth hormone treatment outcomes: preliminary analysis of the national cooperative growth study database. Pediatrics. 1999 Oct;104(4 Pt 2):1028-31.

46 Cohen P, Germak J, Rogol AD, Weng W, Kappelgaard AM, Rosenfeld RG; American Norditropin Study Group. Variable degree of growth hormone $(\mathrm{GH})$ and insulin-like growth factor (IGF) sensitivity in children with idiopathic short stature compared with GH-deficient patients: evidence from an IGFbased dosing study of short children. J Clin Endocrinol Metab. 2010 May;95(5):2089-98.

47 Wagner IV, Paetzold C, Gausche R, Vogel M, Koerner A, Thiery J, et al. Clinical evidencebased cutoff limits for GH stimulation tests in children with a backup of results with reference to mass spectrometry. Eur J Endocrinol. 2014 Sep;171(3):389-97.
48 Dassa Y, Crosnier H, Chevignard M, Viaud M, Personnier C, Flechtner I, et al. Pituitary deficiency and precocious puberty after childhood severe traumatic brain injury: a longterm follow-up prospective study. Eur J Endocrinol. 2019 May: 180(5):281-90.

49 Stanley TL, Levitsky LL, Grinspoon SK, Misra M. Effect of body mass index on peak growth hormone response to provocative testing in children with short stature. J Clin Endocrinol Metab. 2009 Dec;94(12):4875-81.

50 Martínez AS, Domené HM, Ropelato MG, Jasper HG, Pennisi PA, Escobar ME, et al. Estrogen priming effect on growth hormone $(\mathrm{GH})$ provocative test: a useful tool for the diagnosis of GH deficiency. J Clin Endocrinol Metab. 2000 Nov;85(11):4168-72.

51 Marin G, Domené HM, Barnes KM, Blackwell BJ, Cassorla FG, Cutler GB Jr. The effects of estrogen priming and puberty on the growth hormone response to standardized treadmill exercise and arginine-insulin in normal girls and boys. J Clin Endocrinol Metab. 1994 Aug. 79(2):537-41.

52 Westphal O. Evaluation of GH secretion. In: Laron Z, Butenandt O, Raiti S, editors. Conical use of growth hormone. Pediatric and adolescent endocrinology. Basel: Karger; 1987. p. 88-95.

53 Rikken B, Wit JM. Prepubertal height velocity references over a wide age range. Arch Dis Child. 1992 Oct;67(10):1277-80.

54 Bayer LM, Bayley N. Growth pattern shifts in healthy children: spontaneous and induced. J Pediatr. 1963 May;62(5):631-45.

55 Dauber A. New genetic tools in the diagnosis of growth defects. Growth Horm IGF Res. 2018 Feb;38:24-8.

56 Dauber A, Rosenfeld RG, Hirschhorn JN. Genetic evaluation of short stature. J Clin Endocrinol Metab. 2014 Sep;99(9):3080-92.

57 Murray PG, Clayton PE, Chernausek SD. A genetic approach to evaluation of short stature of undetermined cause. Lancet Diabetes Endocrinol. 2018 Jul;6(7):564-74.

58 Wit JM, Oostdijk W, Losekoot M, van Duyvenvoorde HA, Ruivenkamp CA, Kant SG. MECHANISMS IN ENDOCRINOLOGY: novel genetic causes of short stature. Eur J Endocrinol. 2016 Apr;174(4):R145-73.

59 Guo MH, Shen Y, Walvoord EC, Miller TC, Moon JE, Hirschhorn JN, et al. Whole exome sequencing to identify genetic causes of short stature. Horm Res Paediatr. 2014;82(1):4452.

60 Freire BL, Homma TK, Funari MF, Lerario AM, Vasques GA, Malaquias AC, et al. Multigene Sequencing Analysis of Children Born Small for Gestational Age With Isolated Short Stature. J Clin Endocrinol Metab. 2019 Jun; 104(6):2023-30.

61 Wakeling EL, Brioude F, Lokulo-Sodipe O, O'Connell SM, Salem J, Bliek J, et al. Diagnosis and management of Silver-Russell syndrome: first international consensus statement. Nat Rev Endocrinol. 2017 Feb;13(2): 105-24.
62 Gravholt $\mathrm{CH}$, Andersen NH, Conway GS, Dekkers OM, Geffner ME, Klein KO, et al.; International Turner Syndrome Consensus Group. Clinical practice guidelines for the care of girls and women with Turner syndrome: proceedings from the 2016 Cincinnati International Turner Syndrome Meeting. Eur J Endocrinol. 2017 Sep;177(3):G170.

63 Prakash S, Guo D, Maslen CL, Silberbach M Milewicz D, Bondy CA; GenTAC Investigators. Single-nucleotide polymorphism array genotyping is equivalent to metaphase cytogenetics for diagnosis of Turner syndrome. Genet Med. 2014 Jan;16(1):53-9.

64 Richards S, Aziz N, Bale S, Bick D, Das S, Gastier-Foster J, et al.; ACMG Laboratory Quality Assurance Committee. Standards and guidelines for the interpretation of sequence variants: a joint consensus recommendation of the American College of Medical Genetics and Genomics and the Association for Molecular Pathology. Genet Med. 2015 May; 17(5):405-24.

65 Pollard S, Sun S, Regier DA. Balancing uncertainty with patient autonomy in precision medicine. Nat Rev Genet. 2019 May;20(5): 251-2.

66 Grimberg A, DiVall SA, Polychronakos C, Allen DB, Cohen LE, Quintos JB, et al.; Drug and Therapeutics Committee and Ethics Committee of the Pediatric Endocrine Society. Guidelines for Growth Hormone and InsulinLike Growth Factor-I Treatment in Children and Adolescents: Growth Hormone Deficiency, Idiopathic Short Stature, and Primary Insulin-Like Growth Factor-I Deficiency. Horm Res Paediatr. 2016;86(6):361-97.

67 Schrier L, de Kam ML, McKinnon R, Che Bakri A, Oostdijk W, Sas TC, et al. Comparison of body surface area versus weight-based growth hormone dosing for girls with Turner syndrome. Horm Res Paediatr. 2014;81(5): 319-30.

68 Hughes IP, Harris M, Cotterill A, Ambler G, Cowell CT, Cutfield WS, et al. Comparison of weight- vs body surface area-based growth hormone dosing for children: implications for response. Clin Endocrinol (Oxf). 2014 Mar;80(3):384-94.

69 Wit JM, Ranke MB, Albertsson-Wikland K, Carrascosa A, Rosenfeld RG, Van Buuren S, et al. Personalized approach to growth hormone treatment: clinical use of growth prediction models. Horm Res Paediatr. 2013; 79(5):257-70.

70 Deal CL, Tony M, Höybye C, Allen DB, Tauber M, Christiansen JS. 2011 Growth Hormone in Prader-Willi Syndrome Clinical Care Guidelines Workshop Participants. Growth Hormone Research Society workshop summary: consensus guidelines for recombinant human growth hormone therapy in Prader-Willi syndrome. J Clin Endocrinol Metab. 2013 Jun;98(6):E1072-87. 
71 Ranke MB, Lindberg A, Mullis PE, Geffner ME, Tanaka T, Cutfield WS, et al. Towards optimal treatment with growth hormone in short children and adolescents: evidence and theses. Horm Res Paediatr. 2013;79(2):5167.

72 Kriström B, Aronson AS, Dahlgren J, Gustafsson J, Halldin M, Ivarsson SA, et al. Growth hormone $(\mathrm{GH})$ dosing during catch-up growth guided by individual responsiveness decreases growth response variability in prepubertal children with GH deficiency or idiopathic short stature. J Clin Endocrinol Metab. 2009 Feb;94(2):483-90.

73 Schönau E, Westermann F, Rauch F, Stabrey A, Wassmer G, Keller E, et al.; German Lilly Growth Response Study Group. A new and accurate prediction model for growth response to growth hormone treatment in children with growth hormone deficiency. Eur J Endocrinol. 2001 Jan;144(1):13-20.

74 Cohen P, Rogol AD, Howard CP, Bright GM, Kappelgaard AM, Rosenfeld RG; American Norditropin Study Group. Insulin growth factor-based dosing of growth hormone therapy in children: a randomized, controlled study. J Clin Endocrinol Metab. 2007 Jul; 92(7):2480-6.

75 Cohen P, Weng W, Rogol AD, Rosenfeld RG, Kappelgaard AM, Germak J. Dose-sparing and safety-enhancing effects of an IGF-Ibased dosing regimen in short children treated with growth hormone in a 2-year randomized controlled trial: therapeutic and pharmacoeconomic considerations. Clin Endocrinol (Oxf). 2014 Jul;81(1):71-6.

76 Cohen P, Rogol AD, Weng W, Kappelgaard AM, Rosenfeld RG, Germak J; American Norditropin Study Group. Efficacy of IGF-based growth hormone $(\mathrm{GH})$ dosing in nonGH-deficient (nonGHD) short stature children with low IGF-I is not related to basal IGF-I levels. Clin Endocrinol (Oxf). 2013 Mar;78(3):40514.

77 Decker R, Albertsson-Wikland K, Kriström B, Halldin M, Gustafsson J, Nilsson NÖ, et al.
GH dose reduction maintains normal prepubertal height velocity after initial catch-up growth in short children. J Clin Endocrinol Metab. 2019 Mar;104(3):835-44.

78 Bakker NE, van Doorn J, Renes JS, Donker GH, Hokken-Koelega AC. IGF-1 levels, complex formation, and IGF bioactivity in growth hormone-treated children with Prader-Willi syndrome. J Clin Endocrinol Metab. 2015 Aug;100(8):3041-9.

79 Lebl J, Průhová S, Zapletalová J, Pechová M. IGF-I resistance and Turner's syndrome. J Pediatr Endocrinol Metab. 2001 Jan;14(1): 37-41.

80 Allen DB. Safety of growth hormone treatment of children with idiopathic short stature: the US experience. Horm Res Paediatr. 2011;76(s3 Suppl 3):45-7.

81 Christiansen JS, Backeljauw PF, Bidlingmaier M, Biller BM, Boguszewski MC, Casanueva FF, et al. Growth Hormone Research Society perspective on the development of long-acting growth hormone preparations. Eur J Endocrinol. 2016 Jun;174(6):C1-8.

82 Bang P, Ahmed SF, Argente J, Backeljauw P, Bettendorf $\mathrm{M}$, Bona $\mathrm{G}$, et al. Identification and management of poor response to growthpromoting therapy in children with short stature. Clin Endocrinol (Oxf). 2012 Aug; 77(2):169-81.

83 Bakker B, Frane J, Anhalt H, Lippe B, Rosenfeld RG. Height velocity targets from the national cooperative growth study for first-year growth hormone responses in short children. J Clin Endocrinol Metab. 2008 Feb;93(2): 352-7.

84 Ranke MB, Lindberg A; KIGS International Board. Observed and predicted growth responses in prepubertal children with growth disorders: guidance of growth hormone treatment by empirical variables. J Clin Endocrinol Metab. 2010 Mar;95(3):1229-37.

85 Mauras N, Welch S, Rini A, Klein KO. An open label 12-month pilot trial on the effects of the aromatase inhibitor anastrozole in growth hormone (GH)-treated GH deficient adolescent boys. J Pediatr Endocrinol Metab. 2004 Dec;17(12):1597-606.

86 Carel JC, Eugster EA, Rogol A, Ghizzoni L, Palmert MR, Antoniazzi F, et al.; ESPE-LWPES GnRH Analogs Consensus Conference Group. Consensus statement on the use of gonadotropin-releasing hormone analogs in children. Pediatrics. 2009 Apr; 123(4):e752-62.

87 Mericq MV, Eggers M, Avila A, Cutler GB Jr, Cassorla F. Near final height in pubertal growth hormone (GH)-deficient patients treated with GH alone or in combination with luteinizing hormone-releasing hormone analog: results of a prospective, randomized trial. J Clin Endocrinol Metab. 2000 Feb;85(2): 569-73.

88 Mul D, Wit JM, Oostdijk W, Van den Broeck J; Dutch Advisory Group on Growth Hormone. The effect of pubertal delay by $\mathrm{GnRH}$ agonist in GH-deficient children on final height. J Clin Endocrinol Metab. 2001 Oct; 86(10):4655-6.

89 Allen DB, Backeljauw P, Bidlingmaier M, Biller BM, Boguszewski M, Burman P, et al. GH safety workshop position paper: a critical appraisal of recombinant human GH therapy in children and adults. Eur J Endocrinol. 2016 Feb;174(2):1-9.

90 Garcia JM, Biller BM, Korbonits M, Popovic V, Luger A, Strasburger CJ, et al. Macimorelin as a Diagnostic Test for Adult GH Deficiency. J Clin Endocrinol Metab. 2018 Aug;103(8): 3083-93.

91 Chihara K, Shimatsu A, Hizuka N, Tanaka T, Seino Y, Katofor Y; KP-102 Study Group. A simple diagnostic test using GH-releasing peptide-2 in adult GH deficiency. Eur J Endocrinol. 2007 Jul;157(1):19-27.

92 Asakura Y, Toyota Y, Muroya K, Adachi M. Growth hormone response to GH-releasing peptide-2 in children. J Pediatr Endocrinol Metab. 2010 May;23(5):473-80.

93 Ornitz DM, Legeai-Mallet L. Achondroplasia: Development, pathogenesis, and therapy. Dev Dyn. 2017 Apr;246(4):291-309. 